\title{
FERRAMENTA DE APOIO AOS COMANDANTES DAS OPERAÇÕES DE SOCORRO EM INTERVENÇÕES ESTRUTURAIS DAS EQUIPAS DE BOMBEIROS
}

Pedro Miguel Sousa Barahona, Ana Filomena de Figueiredo Dias, Carla Maria Lopes da Silva Afonso dos Santos

Instituto Politécnico de Beja - IPBeja. Beja, PT. Instituto Politécnico de Beja - IPBeja e Investigador do Centro de Matemática e Aplicações da Universidade Nova de Lisboa, PT. E-mail: ana.dias@ipbeja.pt

\section{RESUMO}

No âmbito das intervenções estruturais, os 1. Comandantes das Operações de Socorro (COS) apenas têm disponíveis os dados facultados pelo alertante, que se revelam insuficientes para uma tomada de decisão informada. Através de uma pesquisa quantitativa, de natureza descritiva, observacional e transversal, com recurso a um questionário dirigido a operacionais que podem ser COS, efetuou-se um levantamento das necessidades de informação dos COS. De acordo com os resultados, conclui-se que o propósito de conhecer os riscos e de delineamento de uma estratégia de combate mais efetiva, mais rápida e mais segura para os operacionais envolvidos, está comprometido pela limitação da informação disponível. Fundamentado nestas conclusões, foi elaborada uma proposta de uma nova ferramenta de suporte aos COS - o Plano de Intervenção Inicial (PII) - que seja um documento de consulta rápida e intuitiva, suprindo as necessidades de informação para os COS.

Palavras-chave: Segurança Contra Incêndio em Edifícios, Comandante das Operações de Socorro, Tomada de Decisão, Intervenções Estruturais.

\section{TOOL TO SUPPORT COS IN STRUCTURAL INTERVENTIONS BY FIREFIGHTERS TEAMS}

\begin{abstract}
In a scenario of structural intervention situation, the On-Scene Commanders (COS) only have at their disposal the data provided by the one who gave the alert, which are insufficient to provide a secure and informed decision-making. Through a quantitative, descriptive, observational, and cross-sectional research, using a questionnaire applied to operational staff who perform the COS function, results a survey of the $\cos$ information needs. According to the results, it is concluded that the purpose of knowing the risks and outlining a more effective, faster and safer combat strategy for operational personnel involved, could be compromised by the limited information available. A proposal for a new support tool for COS function - the Initial Intervention Plan (PII) - was developed, which is a document of quick and intuitive consultation, supplying the needs of information for COS.
\end{abstract}

Keywords: Fire Safety in Buildings, On-Scene Commanders, Decision Making, Structural interventions.

\section{INTRODUÇÃO}

Os edifícios estão sujeitos a diversos riscos, sendo o mais frequente o risco de incêndio. O fogo é conhecido desde a pré-história e sempre trouxe muitos benefícios para 0 homem, no entanto, quando este sai do controlo do Homem, torna-se um problema, e passa a designar-se incêndio ${ }^{1}$.

No âmbito da segurança contra incêndio em edifícios (SCIE), existe legislação específica que prevê os princípios gerais da preservação da vida humana, do ambiente e do património cultural, com o objetivo de reduzir a 
probabilidade de ocorrência de incêndios, limitar o desenvolvimento de eventuais incêndios, circunscrever e minimizar os seus efeitos, facilitar a evacuação e o salvamento dos ocupantes em risco e permitir a intervenção eficaz e segura dos meios de socorro ${ }^{2,3}$. Este estudo centra-se principalmente no último objetivo, que é a intervenção eficaz e segura dos meios de socorro.

$O$ socorro às populações em Portugal assenta principalmente nos Corpos de Bombeiros (CB) voluntários, ainda que essa responsabilidade possa ser partilhada com bombeiros profissionais e mistos e com outros Agentes de Proteção Civil (APC) ou forças de intervenção de proteção e socorro. Esse socorro é efetuado em incêndios, inundações, desabamentos e em todos os acidentes, catástrofes ou calamidades ${ }^{4}$. A legislação refere que o bombeiro é "o indivíduo que, integrado de forma profissional ou voluntária num $C B$, tem por atividade cumprir as missões dos $C B$, nomeadamente a proteção de vidas humanas e bens em perigo, mediante a prevenção e extinção de incêndios, o socorro de feridos, doentes ou náufragos e a prestação de outros serviços previstos nos regulamentos internos" ${ }^{\prime 4}$.

A norma NP 4397 de 2008, define o Risco como a combinação da probabilidade e da(s) consequência(s) da ocorrência de determinado acontecimento perigoso. Contudo, o conceito de risco pode obter várias interpretações. Para um mesmo risco ou perigo existem significados distintos, dependendo das pessoas e do contexto em que se inserem. No entanto, o elemento que é essencialmente comum a todas as definições de riscos é o de existir a possibilidade de perdas ou danos $^{5}$. A norma internacional ISO 45001:2018 define o risco como o estado, mesmo parcial, de deficiência de informações relacionadas com a compreensão ou conhecimento de um acontecimento e é frequentemente expresso em termos de uma combinação das consequências de um evento (incluindo mudanças nas circunstâncias) e a "probabilidade" associada deste poder ocorrer ${ }^{6}$.

Os bombeiros trabalham normalmente em ambientes de risco elevado, com características muito diferenciadas, que podem causar danos físicos ${ }^{7}$. O ambiente hostil em que os bombeiros normalmente desenvolvem a sua atividade gera riscos diferenciados que podem causar danos físicos, com maior ou menor gravidade, ou até mesmo a morte ${ }^{8}$.
A adequada gestão dos riscos, através do delineamento de uma estratégia de combate mais efetiva, mais rápida e mais segura para os operacionais envolvidos, está comprometida pela limitação da informação disponível, evidenciando a necessidade de um documento operacional de fácil e rápida consulta que possa fornecer ao COS a informação necessária.

\section{RISCOS DA ATIVIDADE DE BOMBEIROS}

A incidência de acidentes nos bombeiros é superior à que existe na generalidade das outras classes profissionais ${ }^{9}$, devido aos perigos e riscos com que lidam na sua atividade diariamente.

Os riscos associados ao socorro são transversais a todas as áreas, uma vez que os incidentes onde os bombeiros intervêm ocorrem em todas as atividades da sociedade ${ }^{10}$. Ainda de acordo com estes autores, os bombeiros estão sujeitos a inúmeros fatores de risco profissionais, como os fatores de risco biológicos, químicos, físicos, riscos de acidentes diversos, fatores de risco ergonómicos, organizacionais e psicossociais. Neste estudo apenas irão ser abordados os riscos a que os bombeiros poderão estar sujeitos em intervenções estruturais.

Relativamente a riscos biológicos, existe exposição em, por exemplo operações de emergência pré-hospitalar ou contacto com cadáveres humanos, situações que podem ocorrer em intervenções estruturais. Os fatores de risco associados a agentes biológicos são responsáveis por algumas doenças profissionais e são transmitidas por são transmitidas por fungos, bactérias ou vírus.

Os fatores de risco químico, são os agentes ambientais causadores de doenças profissionais, devido à sua ação química sob o organismo dos bombeiros. Destacam-se, nos incêndios estruturais, a exposição a atmosferas perigosas com a presença de gases tóxicos e venenosos (monóxido de carbono, dióxido de carbono, acido clorídrico, acido cianídrico, dióxido de azoto, fosgénio, etc.), assim como os fumos, formados pela suspensão de pequenas partículas de carbono, alcatrão e poeiras que se combinam facilmente com os gases aquecidos e com o vapor de água resultante do próprio combate ${ }^{7}$.

Em termos de risco físicos, podemos referir o colapso de tetos, telhados e paredes; exposição ao calor que pode provocar queimaduras e stresse térmico; exposição ao 
ruído excessivo quando se encontram junto de equipamentos ruidosos; exposição a vibrações devido à utilização de mangueiras de grande caudal ou à condução de veículos pesados; ferimentos devido a acidentes durante a resposta a emergências, como queda em altura (escadas, colapso de estruturas); queda de objetos; esmagamento por colapso de estruturas edificadas; risco de incêndio e explosão devido a ignição súbita de gases, explosão de objetos no Teatro de Operações (TO) ${ }^{11}$.

A movimentação manual de cargas pesadas e/ou difíceis de transportar, mangueiras de grande caudal e equipamento de proteção individual pesado e adoção de posturas desconfortáveis no combate a incêndios estruturais, podem originar lesões musculosqueléticas.

Estão expostos a fatores que provocam stresse psicológico, como a pressão de tempo, a alternância entre períodos calmos e de grande agitação; horários de trabalho longos; falta de autonomia; realização de turnos rotativos diurnos e noturnos, exigências emocionais elevadas no trabalho e difícil conciliação entre a vida profissional e pessoal. Estes constrangimentos podem levar à síndrome Burnout e à síndrome de stresse pós-traumático ${ }^{11}$.

Amaro (2009) refere ainda os fatores culturais ou de mentalidade como riscos associados à atividade dos bombeiros, fatores esses que, tal como referido por Amaro (2009) ${ }^{12}$ e, Caldeira \& Vicente $(2006)^{13}$ resultam:

- do desconhecimento ou não cumprimento da legislação de Segurança e Saúde no Trabalho aplicável aos corpos de bombeiros;

- de legislação desajustada face aos riscos a que os bombeiros estão expostos (como exemplo o da não obrigatoriedade do uso de cinto de segurança nas viaturas dos bombeiros);

- "a criação e manutenção sistemática da fantasia do bombeiro super-herói".

A minimização destes riscos para os bombeiros que enfrentam o fogo, prendem-se com uma célere tomada de decisão do COS. Esta tomada de decisão está sempre relacionada com o conhecimento que este possui do Teatro de Operações (TO), quanto mais informação este possuir, mais segurança vai existir para os operacionais que enfrentam as chamas, e menos danos para os proprietários e para o ambiente ${ }^{10}$.

\section{INTERVENÇÕES EM INCÊNDIOS EM EDIFÍCIOS}

De acordo com o Sistema de Gestão de Operações (SGO) sempre que uma equipa de qualquer APC seja acionada para uma ocorrência, o chefe da primeira equipa que chega ao local assume a função de COS, garantindo o desenvolvimento de um sistema evolutivo de comando e controlo adequado à situação em curso. O COS é um elemento tecnicamente qualificado e dotado de autoridade para atribuir missões operacionais, articular as forças que the forem atribuídas, dirigir e regular aspetos logísticos de interesse imediato para as operações e gere a informação operacional. A função de COS é a única, prevista no SGO que é obrigatória e permanente em qualquer operação de proteção e socorro, independentemente da sua tipologia, dimensão, complexidade ou duração ${ }^{14}$.

Nas intervenções estruturais, existem diversas atividades a desenvolver pelas equipas de intervenção, incluindo os aspetos táticos e os procedimentos de segurança a elas associados. Estas operações de combate desenvolvem-se, sequencialmente, através das seguintes fases da marcha geral das operações de combate a incêndios:

a) Reconhecimento - Avaliação das condições em que se desenvolve qualquer incidente, para dimensionar as ações a tomar;

b) Salvamentos - Prioritários nas operações, sempre que existam ou se suspeite que existam vítimas em perigo;

c) Estabelecimento dos meios de ação Execução das tarefas necessárias, de acordo com o plano de ação definido pelo COS;

d) Ataque e proteção - Combate ao incidente, para limitar a sua propagação no espaço e no tempo;

e) Rescaldo - Destina-se a eliminar todos os focos em combustão, limitando o risco de reacendimento;

f) Vigilância - As equipas permanecem no local, exercendo uma ação de vigilância, impedindo o reacendimento.

Todas estas fases, devem ser seguidas em qualquer operação de combate a incêndios, com exceção das fases de salvamentos e vigilância, que poderão não ser necessárias ${ }^{14}$.

Todo o processo de decisão é sustentado na recolha de informação inicial. O reconhecimento é um processo em que se realiza uma apreciação 
dos problemas e condições concretas, que servem de base à definição do plano de ação, garantindo assim uma maior possibilidade de sucesso no cumprimento dos objetivos.

Neste processo de reconhecimento, o COS terá de considerar grande diversidade de fatores para que a sua decisão seja mais eficaz, contudo, considerando que existem fatores que não se podem controlar, o reconhecimento é uma responsabilidade na qual participam todos quantos estão envolvidos no TO. São as informações que se obtêm no reconhecimento que determinam quais as tarefas a executar, onde, quando e como serão executadas. 0 processo de reconhecimento inicia-se na central telefónica do corpo de bombeiros, com a receção da chamada de socorro e mantém-se até ao final da ocorrência. Como é um processo de obtenção de informação, deve sempre que possível incluir todas as informações obtidas durante a fase de planeamento prévio através dos Planos Prévios de Intervenção (PPI), se existirem.

Os PPI são instrumentos à disposição dos APC, possibilitando 0 desencadeamento sistematizado da resposta a operações de proteção e socorro, permitindo conhecer antecipadamente os cenários e os meios, garantindo-se assim uma melhor gestão integrada de recursos. Os PPI têm como principais objetivos conseguir a otimização da resposta e a integração dos meios dos diversos APC que possam vir a intervir em cada cenário previsto e orientar, com base nas indicações dos Planos de Emergência, a resposta operacional ${ }^{15}$.

Segundo Sousa $(2007)^{16}$, ao estabelecerse uma analogia da doutrina militar para a tomada de decisão nas operações dos bombeiros em intervenções estruturais, verifica-se que o coS determina a missão através do seu reconhecimento, ao identificar os fatores fundamentais que indicam que tipo de estratégia de combate que é necessário empreender. A missão envolve as tarefas que têm de ser cumpridas pela equipa. A análise do fogo deve ter em consideração as informações disponíveis sobre o seu potencial, as características do combustível, a sua localização e extensão, identificando e avaliando o seu comportamento, sendo necessário ainda saber a Utilização Tipo (UT), categoria de risco, ocupação do edifício, assim como o tipo de construção, altura e implementação. A análise do terreno ajuda a caracterizar os perigos e riscos circundantes, as ameaças e pontos sensíveis, assim como as acessibilidades aos veículos de socorro. Quanto às condições meteorológicas, têm sempre uma influência direta no comportamento de qualquer incêndio, pois fatores como temperatura e humidade relativa do ar, a velocidade e direção do vento, ajudam a identificar o potencial de desenvolvimento do sinistro. As condições meteorológicas e o terreno têm implicações operacionais, com efeitos diretos nas operações de socorro, e nas operações de apoio ao combate e logística.

O COS deve avaliar todos os recursos humanos e materiais, presentes ou previstos e colocados à sua disposição. Esta avaliação não se deve cingir apenas à quantidade, mas também à sua adequação relativamente à situação, assim como do estado físico e psicológico das equipas e do seu nível de treino e formação. Também devem ser considerados neste ponto os hidrantes e os sistemas de proteção passivos e ativos contra incêndios do edifício ${ }^{16}$.

Para um reconhecimento eficaz, o COS tem de recolher os seguintes dados:

- existência de vítimas ou pessoas em perigo;

- tipo de construção, ocupação, área de implementação e altura do edificado;

- localização e extensão do incêndio;

- riscos envolventes;

- capacidade dos hidrantes locais;

- condições meteorológicas;

- presença de matérias perigosas.

No reconhecimento, o processo de recolha de informações é crucial e torna-se sempre mais rico à chegada ao TO devido à observação visual deste. A cada instante o COS deve fazer um esforço de síntese, permanecer afastado do cenário para ser objetivo e poder tomar as decisões adequadas às necessidades do TO, tendo sempre presente que não existem soluções perfeitas e que sempre existirão incertezas.

\section{AVERIGUAÇÃO DA NECESSIDADE DE UM DOCUMENTO DE APOIO AOS COS}

Verificando-se que a informação inicial fornecida ao 1.o COS é apenas a que o alertante fornece, que é a sua identificação, a localização e a indicação do tipo de ocorrência. Foram analisados exaustivamente os conteúdos dos documentos formais exigidos pela legislação de SCIE, que são o projeto de SCIE e as Medidas de Autoproteção (MAP). 
O projeto de SCIE é o documento que define as características do edifício quanto a essa especialidade e que possui uma memória descritiva e justificativa onde são analisadas as condições exteriores e de evacuação, definidas as resistências ao fogo dos elementos de construção, reação ao fogo dos materiais, instalações técnicas e os equipamentos e sistemas de segurança, também tem de possuir peças desenhadas, ou seja, é um documento técnico ${ }^{2,3}$.

As MAP consistem num conjunto de documentos, procedimentos e formação, que visam a Organização e Gestão da Segurança, compostas pelos registos de segurança; medidas preventivas que tomam a forma de procedimentos de prevenção ou planos de prevenção; medidas de intervenção em caso de incêndio que podem ser procedimentos de emergência ou planos de emergência internos; ações de sensibilização e formação em SCIE e simulacros.

Considerando que existem documentos que possuem bastante informação, mas que são extensos e muito técnicos pode considerar-se uma grande lacuna na fase inicial de combate aos incêndios estruturais existir tão pouca informação. A informação existente nesses documentos pode ter mais valências, daí ter-se criado um documento operacional com informações retiradas dos documentos já existentes e adaptados exclusivamente a este tipo de ocorrências.

\section{MÉTODOS}

Colocando o foco no objetivo de validação da necessidade de uma ferramenta que auxilie o $\cos$ a efetuar um célere e eficaz reconhecimento para uma mais segura tomada de decisão, desenvolveu-se um estudo quantitativo, de natureza descritiva, observacional e transversal.

Considerando que são os bombeiros com cargos de chefia intermédia que, ao serem mobilizados para as intervenções, assumem na fase inicial da operação a função de $\operatorname{COS}$, o universo deste estudo é composto pelos bombeiros com a graduação de Oficiaisbombeiros, Chefes, Subchefes e Bombeiros de 1a, existentes nos $15 \mathrm{CB}$ do distrito de Beja, que totalizam 190 elementos.

Para a recolha de dados foi elaborado um questionário, organizado em 3 grupos de questões. 0 primeiro grupo focado na caraterização sociodemográfica dos bombeiros, o segundo grupo nos dados operacionais e no 3. 으 grupo foram incluídas as questões relacionadas com a perceção e opinião dos bombeiros em relação aos aspetos que fundamentam a necessidade da ferramenta, que se designou Plano de Intervenção Inicial (PII).

Nas questões Q.1 a Q.5 o grau de concordância / discordância foi estabelecido através de uma escala de Likert de cinco pontos, correspondentes a 1 - Discordo totalmente; 2 Discordo; 3 - Não concordo nem discordo; 4 Concordo; 5 - Concordo totalmente.

Na questão Q.6, incidente no grau de importância atribuído à necessidade implementação de uma ferramenta de apoio à decisão, recorreu-se também a uma escala de Likert de cinco pontos correspondentes a $1-$ Sem qualquer importância; 2 - Pouco importante; 3 Importante; 4-Muito importante; 5 - Essencial.

Antes da aplicação do questionário realizou-se um pré-teste, a sete bombeiros do quadro de comando e da carreira de oficiaisbombeiros do quadro ativo do CB de Beja. Deste processo resultou a necessidade de ajustar duas das questões do questionário, que foram reformuladas.

\section{RESULTADOS E DISCUSSÃO}

A taxa de resposta foi de $85,8 \%$, o que corresponde à receção de 163 questionários válidos.

Todos os inquiridos são de nacionalidade portuguesa e $87,1 \%$ pertence ao género masculino. A faixa etária dos 36 aos 45 anos é a mais representativa para as graduações de Bombeiro de 1a e Subchefe, à qual correspondem 77 indivíduos. Com maior incidência na faixa etária dos 46 aos 55 anos, estão os postos de chefe e de Oficial Bombeiro, com 14 e 3 indivíduos respetivamente. A média de idades do conjunto dos inquiridos é 43,9 anos. Na amostra não existe nenhum individuo com mais de 65 anos, pois é esta a idade limite de permanência nas carreiras de bombeiro. $O$ número de indivíduos casados ou em união de facto é o mais expressivo em todas as graduações, representando $80,4 \%$ (131) dos bombeiros inquiridos. $O$ posto de bombeiro de 1. a representa o maior $\mathrm{n}$. - de inquiridos com $42,3 \% \mathrm{e}$ os níveis de habilitações literárias mais representativos são o 3. ciclo e o secundário. Os bombeiros com vínculo profissional, representam 
$60,7 \%$ dos inquiridos, e os restantes $39,3 \%$ (64) são bombeiros voluntários.

Nos questionários validados observou-se que, dos inquiridos que responderam já ter sofrido acidentes $(36,2 \%)$ na atividade de bombeiros, os postos de subchefes e os bombeiros de 1 a são os que mais se destacam, representando $40,7 \%$ e $37,3 \%$, respetivamente. Relativamente aos acidentes presenciados, o seu valor absoluto decresce $(23,3 \%)$, mas são novamente as mesmas graduações que se distinguem, com os subchefes a presenciarem 15 acidentes $(39,5 \%)$, e os bombeiros de 1. presenciaram 14 acidentes (36,8\%). Verifica-se que o número de acidentes com consequências ligeiras (69) é superior aos que provocaram ferimentos graves (28). Relativamente ao fator graduação, os inquiridos com 0 posto de subchefe relataram ter sofrido um total 24 ferimentos (6 graves e 18 ligeiros), seguindo os bombeiros de 1 a com um acumulado de 22 lesões, das quais 6 foram graves. Quanto aos acidentes presenciados, existe um equilíbrio no número de acidentes referidos pelos inquiridos com o posto de subchefe e bombeiro de $1^{\mathrm{a}}$, que resultaram num total de 15 e 14 ferimentos, respetivamente.

Quanto ao número de intervenções estruturais em que costumam participar por ano, a grande maioria, 115 indivíduos (70,6\%) respondeu que participa em menos de 10 intervenções deste tipo por ano, a média da frequência com que a população assume o COS nas intervenções estruturais é de 3,6 intervenções/ano, representando na escala da resposta à questão n. 0 2, uma incidência entre o 'ocasionalmente' e o 'frequentemente'. Tais resultados estão diretamente ligados ao posto dos inquiridos, ou seja, quanto maior a sua graduação maior é a frequência, sendo 'ocasionalmente' o mais frequente para os bombeiros de 1a e 'frequentemente' para os oficiais bombeiros. A população inquirida considera que 'frequentemente' tem conhecimento sobre a sua área de intervenção e os acessos ao TO. Os resultados revelaram também que 'raramente' o COS tem ao seu dispor conhecimento relativo à estrutura e características dos edifícios, da sua ocupação e das medidas passivas, ativas e de autoproteção existentes. No que respeita ao documento à disposição mais utilizado, a folha de serviço que as centrais telefónicas dos CB preenchem, aquando do alerta, é o documento mais utilizado, e 93,6\% (153) dos bombeiros referiram usá-lo no trajeto e $72,4 \%$ (118) referiram usá-lo no TO. Relativamente à informação disponível nesse documento, a esmagadora maioria dos COS $(93,6 \%)$ referiram que apenas dispõem da informação relativa à localização do sinistro, hora de alerta e identificação do alertante.

No que respeita à perceção dos inquiridos sobre perigos e riscos nas intervenções estruturais e apreciação da necessidade da existência de informação que melhore a capacidade de decisão, os resultados apontam para uma concordância quase absoluta com a existência de riscos e perigos na atividade e com a necessidade de aceder a informação relevante que auxilie na sua capacidade de decisão.

A análise dos resultados referentes às questões que pretenderam aferir o modo como os inquiridos avaliam e valorizam a capacidade de decisão, a capacidade de reconhecimento e a importância da informação, foi realizada em conjunto, uma vez que têm o mesmo fator em comum: a Informação. Pretendendo-se estimar de que forma os inquiridos valorizam a existência de um documento que contenha toda a informação necessária ao cumprimento das suas competências, foi apurado que em relação à capacidade de decisão a existência de um documento com toda a informação sobre o TO é fundamental para a tomada de decisão do COS. Em relação à capacidade de reconhecimento, os inquiridos mencionam que a informação de que dispõem nem sempre é suficiente $(75,5 \%)$ e que nem sempre é fácil fazer o reconhecimento, no entanto concordam que a existência de um documento com toda a informação sobre o edifício pode melhorar a sua capacidade de reconhecimento (90,18\%). Quanto ao último ponto, a importância da informação, afirmam que quanto mais informações estiverem disponíveis mais fácil é planear $(96,93 \%)$, valorizam o conhecimento atempado do TO $(67,48 \%)$ e referem ainda que a existência de um documento com toda a informação sobre o TO facilita todo o seu trabalho $(92,6 \%)$. As respostas dos inquiridos a estas 3 questões demonstram que estes valorizam de sobremaneira a influência decisiva que a informação tem na sua capacidade de reconhecimento e tomada de decisão.

A valoração da importância da disponibilidade de informação relativa às intervenções estruturais, foi feita com base num conjunto de 20 afirmações, referentes à área de atuação e acessibilidades; ·medidas passivas e 
ativas do edifício. Da análise das respostas conclui-se que os inquiridos, no âmbito das questões sobre a área de atuação e acessibilidades, consideram muito importante o conhecimento sua área de atuação $(99,39 \%)$, os acessos bem como o caminho otimizado para chegar ao TO $(98,16 \%)$, o sentido de trânsito dos acessos ao TO $(98,16 \%)$ e as acessibilidades aos meios de socorro $(98,77 \%)$. Quanto às medidas passivas do edifício é importante conhecer o tipo de edifício e a sua configuração (altura e pisos abaixo do piso de referência), a população e a UT do edifício onde ocorre o sinistro, e a existência de compartimentação corta-fogo. Em relação às medidas ativas, os inquiridos consideram importante saber se existem sistemas automáticos de deteção de incêndios ou de desenfumagem $(96,63 \%)$, os meios de 1 ạ intervenção (extintores, carretéis, rede de incêndio armada) implementados e a sua localização $(97,55 \%)$, os caminhos de evacuação $(97,55 \%)$ e a localização do ponto de encontro (96,93\%). Também consideraram importante saber se existem MAP implementadas $(95,71 \%)$. Constata-se que os inquiridos consideram muito importante conhecer toda a informação relacionada com o edifício em causa e com toda a área envolvente.

Quanto à valoração da existência de uma ferramenta/documento de suporte de apoio à decisão, envolvida em 5 afirmações, relacionadas com a perceção de perigos e riscos; segurança; reconhecimento; capacidade de decisão e informação, os inquiridos consideram de extrema importância a existência de um documento, com toda a informação compilada e de fácil e rápido acesso, como ferramenta disponível de apoio à intervenção em estruturas. Em termos médios o grau de importância atribuído pelos inquiridos à existência da ferramenta corresponde a 4,7. Verificando-se que $72,4 \%$ (118) dos inquiridos consideram a existência da ferramenta como 'essencial' ao cumprimento da sua missão, $23,3 \%$ (38) consideram como 'muito importante' e apenas 4,3\% (7) responderam 'importante'.

Os resultados demostram, que a informação de dispõem os COS nem sempre é suficiente, o que dificulta a etapa do reconhecimento, primordial na tomada de decisão e na resolução da ocorrência., e também que maior informação é associada a maior facilidade em fazer um bom reconhecimento, um planeamento mais eficaz e efetuar uma tomada de decisão de forma mais rápida e segura.
Os resultados obtidos apontam para a necessidade premente da criação de uma ferramenta documental que auxilie os $\operatorname{COS}$ na tomada de decisão, de modo que o conhecimento atempado dos TO e, consequentemente, dos riscos existentes, possa levar a uma intervenção que permita maximizar a segurança para os bombeiros.

\section{PROPOSTA DE CRIAÇÃO DE FERRAMENTA DE APOIO AOS COS}

De acordo com os resultados do inquérito que dirigimos aos operacionais que desempenham a função de $\operatorname{coS}$ em intervenções estruturais, conclui-se que a informação inicial que lhes é disponibilizada é insuficiente e que a informação extra de que podiam dispor se encontra em documentos de complexa e morosa consulta e que estas limitações constituem obstáculos para o conhecimento atempado dos riscos e 0 delineamento de estratégias adequadas, quer em termos de efetividade quer em termos de segurança das operações. Estas constatações culminam na perceção da necessidade de informação clara e focalizada, que sustente uma tomada de decisão mais célere e propicie operações mais seguras para estes profissionais.

Tendo como alicerce os documentos formais à disposição dos COS, desenvolvemos uma proposta de ferramenta para apoio a este tipo de intervenções exclusivamente, que se designou PII e tem de conter um conjunto de informações de modo a responder às necessidades dos chefes de equipa, nomeadamente: perigos e riscos existentes; área de atuação, acessibilidades, implantação da estrutura; medidas passivas e ativas do edifício.

Considerando que as informações relevantes à criação da ferramenta estão vertidas nas MAP de cada edifício, torna-se importante que seja alterado o seu processo de aprovação e emissão de pareceres, pelo que se propõe que, após a apreciação pela Autoridade Nacional de Emergência e Proteção Civil (ANEPC), um dos exemplares entregues pelo requerente seja enviado aos Serviços Municipais de Proteção Civil (SMPC), sendo esta a entidade responsável pela elaboração uniforme, de estrutura homogénea, para uma consulta rápida e intuitiva, vinculandoos ao processo.

Assim, o PII visa conseguir a otimização da resposta em cada cenário previsto de intervenção estrutural e orientar, com base nas 
indicações das MAP implementadas, a respetiva resposta operacional das equipas de primeira intervenção.

O PII está estruturado de modo a fornecer informações ao chefe da 1. a equipa de forma sequencial, tais como o percurso, a caracterização do edifício, identificação dos riscos, os equipamentos de 1a e 2a intervenção existentes, sua localização e a localização de hidrantes. São fornecidas também as plantas de implantação, de prevenção e de segurança. O PII é composto por cinco itens.

O primeiro item é a primeira página (ou capa) e fornece a informação relativa ao documento, identificação do documento: onde constam o nome, a referência, a versão e a revisão, a data da elaboração e os dados relativos à instituição (nome, fotografia, morada, freguesia, atividade desenvolvida e o proprietário). Na capa apresenta-se a UT e a categoria de risco do edifício.

A página seguinte descreve o percurso para os meios de socorro. Relativamente aos itens 'Percurso' e 'Localização de hidrantes', a sua elaboração recorre à plataforma SIG da Empresa Municipal de Águas e Saneamento (EMAS) a quem foi atribuída a responsabilidade do cadastro e manutenção dos hidrantes existentes no concelho de Beja. Esta plataforma resulta de uma parceria entre a EMAS, o SMPC e o CB de Beja, e fornece aos seus utilizadores a localização de todos os hidrantes cadastrados, todas as suas características (localização, tipo, diâmetro, pressão, no de saídas, estado de operacionalidade, data da sua verificação, etc.). Sendo uma plataforma SIG editável, permite traçar os percursos otimizados e alternativos a percorrer pelos meios de socorro. Ainda neste ponto são identificadas as acessibilidades dos meios de socorro ao edifício e a ordem de saída dos meios a mobilizar, de acordo com a grelha de alarmes implementada no CB.

No ponto 2 do PII está a ficha técnica do edifício, com a seguinte informação: identificação do estabelecimento, caracterização do espaço, população total, o horário de funcionamento e o sistema de vigilância.

Em seguida, são identificados os riscos existentes no edifício e na sua envolvente:

- Riscos internos (como a existência de quadros elétricos, rede de gás, termoacumulador e cozinhas, copas, lavandarias, etc.;
- Riscos externos, como vias de circulação, edifícios nas proximidades (recintos de espetáculo, indústrias, armazéns diversos, etc.);

- Quanto às fontes de energia, foram identificadas a eletricidade, o gás e a rede de água, encontrando-se devidamente listadas, considerando o tipo de equipamento e a localização.

No ponto 4 encontra-se o levantamento de meios e recursos existentes no edifício. Devem ser listados todos os equipamentos de 1a e 2. a intervenção e os recursos à disposição, tais como, iluminação de emergência, sinalização de segurança, sistema de alarme e alerta, e o ponto de encontro previsto nas MAP. Também neste ponto, através da plataforma SIG, apresenta-se a localização dos hidrantes nas proximidades do estabelecimento e que poderão ser uteis à intervenção dos bombeiros. O mapa base utilizado é o mapa de pormenor de ruas, com os números de polícia de todos os edifícios,

Por último, são vertidas no PII as plantas de implantação e de segurança do edifício, constantes nas MAP. Estas plantas são de uma importância determinante para o PII, uma vez que permite aos utilizadores um conhecimento pleno sobre a disposição, compartimentação e recursos do edifício.

\section{CONSIDERAÇÕES FINAIS}

A informação disponibilizada quando é dado o alerta é muitas das vezes insuficiente tornando mais complicada a tomada de decisão do COS, especialmente em intervenções estruturais. Constatou-se que a grande maioria dos COS em intervenções estruturais considera indispensável conhecer toda a informação relacionada com o edifício e com a área envolvente, para maximizar a segurança dos bombeiros envolvidos. Perante a apuração da insuficiência da informação de que dispõem, revelou-se de extrema importância a existência de um documento com toda a informação compilada e colocada à sua disposição, como ferramenta disponível de apoio à decisão, muito intuitiva e de fácil e rápida consulta.

Ficando evidente a relação entre a necessidade de existência de uma ferramenta de apoio à decisão, com a identificação dos perigos $\mathrm{e}$ riscos da atividade, com a forma como os inquiridos valorizam a segurança, com a complexidade na análise da zona de intervenção 
e com a informação à sua disposição, nas intervenções estruturais.

Assim, em face da forma consistente e essencial com que os bombeiros valorizam a disponibilização de informação com vista à segurança das missões que lhes são confiadas, é justificada a criação de uma ferramenta de suporte de apoio à decisão que sustente todas as intervenções estruturais, o PII.

O PII abrange três domínios: a localização do sinistro, o trajeto e a envolvente do local de ocorrência. Acompanha o procedimento atual de emergência seguido pelos $C B$, estabelece os princípios funcionais e orientadores aplicados às intervenções estruturais e identifica todas as informações e recursos do edifício, com vista a uma melhor definição da atuação do chefe da primeira equipa de bombeiros nos TO.

Ao existir disponibilização desta informação tão pertinente, o COS, consegue traçar a estratégia de combate mais atempadamente, o que melhora a segurança destes operacionais. A segurança é reforçada uma vez que existem plantas do edifício, ou seja, os bombeiros já não entram num edifício que desconhecem totalmente. É-lhes facultada a localização dos meios de 1. a e 2. a intervenção e quando entram no edifico já conhecem quer os riscos internos quer externos.

Ficou evidente a relação entre a necessidade de existência de uma ferramenta de apoio à decisão, com a identificação dos perigos e riscos da atividade e mesmo da zona envolvente pode melhorar substancialmente 0 reconhecimento e a tomada de decisão em intervenções estruturais ${ }^{10}$. Assim, ao melhorar a estratégia de combate ao incêndio o PII ajuda a minorar os riscos profissionais destes trabalhadores, pois podem reduzir o seu tempo de exposição aos agentes contaminantes, permitindo-lhes também um maior conhecimento dos riscos internos e externos que vai permitir uma maior segurança durante toda a intervenção.

\section{Referências}

1. Gomes C. R. A Importância dos Equipamentos de Segurança Contra Incêndio nas Empresas. Colloquium Exactarum. 2010; 02(01):21-9. DOI: https://doi.org/10.5747/ce.2010.v02.n1.e009

2. Ministério da Administração Interna (Portugal). Lei n.o 123/2019 de 18 de outubro,
Terceira alteração ao Decreto-Lei n.o 220/2008, de 12 de novembro, que estabelece o Regime Jurídico da Segurança contra Incêndio em Edifícios. Ministério de Administração Interna [Internet]. 2019 [citado 2021 Dez 09];7903-22. Disponível em: https://data.dre.pt/eli/declei/220/2008/11/12/p/dre/pt/html.

3. Ministério da Administração Interna (Portugal). Portaria 135/2020 de 2 de junho, 1.a alteração ao Regulamento Técnico de Segurança contra Incêndio em Edifícios (RT-SCIE) emanado pela Portaria n.o 1532/2008 de 29 de dezembro. Diário da República. 2020.

4. Ministério da Administração Interna (Portugal). Decreto-Lei n.o 248/2012 de 21 de novembro, Regulamento Jurídico dos Corpos de Bombeiros [Internet]. Diário da República. 2012 [citado em 2021 Dez 09]; n.o 225/2012, Série I de 2012-. Disponível em: https://dre.pt/application/conteudo/190872.

5. Instituto Português da Qualidade. NP 4397:2008. Sistemas de gestão da segurança e saúde do trabalho [Internet]. Monte de Caparica: Instituto Português da Qualidade; 2008 [citado em 2021 Mar 31]. Disponível em: www.ipq.pt.

6. International Organization for Standardization. ISO 45001:2018: Occupational health and safety management systems. Switzerland: ISO; 2018.

7. Guerra A. Segurança e proteção individual. 2. ed. Sintra: Escola Nacional de Bombeiros; 2005. v. VIII.

8. Amaro A. Subsídios para o estudo da cultura de segurança nos agentes de proteção civil. Territorium: Revista da Associação Portuguesa de Riscos, Prevenção e Segurança. 2014 DOI: https://doi.org/10.14195/16477723211

9. Santos $\mathrm{M}$, Almeida A. Principais riscos e fatores de risco ocupacionais associados aos bombeiros, eventuais doenças profissionais e medidas de proteção recomendadas. Revista Portuguesa de Saúde Ocupacional. 2016;1: S0209.

DOI: 
10. Barahona P, Dias A, Santos C. Professional Risks in the firefighter's activity: a support tool for On-Scene Commanders in structural interventions. Proceedings II International Hazar Scientific Researchs Conference. 2021; Baku. p. 24-35.

11. Costa F. Saúde no trabalho: a realidade de quem socorre. Viana do Castelo: Instituto Politécnico de Viana do Castelo; 2015.

12. Amaro A. O Socorro em Portugal: Organização, formação e cultura de segurança nos corpos de bombeiros, no quadro da proteção civil [dissertação]. Porto: Universidade do Porto; 2009.

13. Caldeira P, Vicente B. Análise e Controlo de Riscos Profissionais nos Bombeiros Voluntários Portugueses. Lisboa: Instituto de Segurança e Higiene no Trabalho (ISHT); 2006.

14. Ministério da Administração Interna (Portugal). Despacho n.o 3317-A/2018 de 3 de abril - Revisão do Sistema de Gestão de Operações (SGO). Diário da República. 2018 abr. 03;2a série:9530-(2) -9530(10).

15. ANPC. Guia para a Elaboração de Planos Prévios de Intervenção - Conceito e Organização. Cadernos Técnicos Prociv. 2009; 11:1-10.

16. Sousa J. Planeamento Táctico e Tomada de Decisão. Comando da Instrução e Doutrina: Exército português - Publicação Doutrinária do Exército (PDE). Lisboa: Exército português; 2007. 